\title{
The Impact of a Ubiquitous Mobile Computing Environment on Design Engineering Education
}

\author{
Scott B. NOKLEBY and Remon POP-ILIEV \\ Faculty of Engineering and Applied Science \\ UOIT-University of Ontario Institute of Technology \\ 2000 Simcoe Street North \\ Oshawa, ON L1H 7K4 \\ CANADA \\ scott.nokleby@uoit.ca and remon.pop-iliev@uoit.ca
}

\begin{abstract}
Providing students with a ubiquitous mobile computing environment is a key component of UOIT's teaching and learning strategy which offered a unique opportunity to build its programs from the ground-up with a laptop program at its centre. While ensuring that its use was considered in every aspect of curriculum development, five undergraduate engineering programs curricula have been developed at the University's Faculty of Engineering and Applied Science (FEAS) with a laptop-supported mobile computing environment at its heart. The laptops are equipped with a suite of program specific software. The focus of this paper is on the pedagogical benefits that have been achieved in design engineering education at FEAS as a result of the students' ubiquitous access to the latest CAD/CAM/CAE and productivity tools. The laptop program enables improved delivery of design engineering training along with the opportunity of implementing novel teaching strategies.
\end{abstract}

\section{Introduction}

From its inception in 2003, UOIT has been a fully laptop-supported university. Each student leases from the University a current model Lenovo (formerly IBM) laptop computer that is replaced on a two year cycle, i.e., the students receive new laptops in Year 1 and Year 3 of their programs. The reason students are required to lease their laptops and not own them outright during their course of studies is due to software licensing issues. To enable the various software packages to be installed, the University must own the machines, hence the need for the lease arrangement. Note that at the end of their program, students can purchase their laptops for a nominal fee of $\$ 1.00$ (with all software removed).
Based on these premises, a design-intensive engineering curriculum is being developed and implemented at UOIT's FEAS. Its ultimate objective is to prepare effectively graduates with useful workplace engineering skills - ready for getting the products right the first time. The impact and benefits of such a tool on design engineering education are discussed in this paper.

\section{Background}

The concept of laptop-supported engineering programs is not new and more and more schools are adopting laptop programs of various forms [1].

McMahon and Pospisil [2] have shown that the laptop environment supports the needs of today's students. Their study showed that students expect the laptop environment to always be available and that the laptops become an integral part of students' lifestyles.

Smith and Trayner [3] have shown the benefits of integrating both face-to-face instruction with online learning. They showed that with proper one preparation can make face-to-face instruction more effective and online collaboration more productive.

Ellis [4] conducted a comparative investigation of the advantages and disadvantages of the traditional form of face-to-face versus online asynchronous communication and collaborative learning. The study revealed that online collaborative learning may be considered advantageous because: (i) it is convenient in time and place; (ii) it is more equitable - especially for quieter students - more students participate; (iii) details of the discussion remain. One can backtrack and reread a message; (iv) allows the more reflective 
thinking student to participate more; (v) the asynchronous nature allows for a more considered response; (vi) the lecturer is seen as a moderator rather than a teacher; (vii) it allows for discussion with students from other class groups; (viii) the lecturer becomes just one of the group in discussion; (ix) there is more freedom and students are more likely to express opinions and comment on other's remarks; and (x) it is possible to choose what to participate in and one can multitask. However, the same study, also identified some disadvantages of online collaborative learning, such as: (i) it is not possible to read face-toface nuances such as body language; (ii) takes away the features of conversation (e.g. immediacy of response, interactivity); (iii) it is difficult to get an indication of depth of feeling or a person's response; (iv) some students rely on others to post contributions in discussions; (v) discussion threading can become confused, allowing discussion to go off-track; (vi) there is a tendency not to post when there is agreement; and (vii) it is possible to opt out of the discussion, and the extended time for the discussion delays conclusions being reached or causes the topic to go off track.

Recently, wireless palm devices have been brought into the focus, facilitating collaborative learning [5].

\section{The Design Engineering-Enabled Mobile Computing Environment at UOIT's FEAS}

Although face-to-face instructor-learner contact in design-engineering classes is irreplaceable, it is yet limited in duration. Therefore, FEAS's engineering curriculum was founded on the notion that every student should have ubiquitous access to a mobile computing environment in addition to the face-to-face communication. To achieve this level of access, students at FEAS are all issued a standard laptop that is equipped with a carefully selected suite of engineering and productivity software of a professional grade. With such a resource available to students, new and advanced methods of engineering education and training can be readily implemented. Within engineering, the software can be divided into two categories: CAD/CAM/CAE software and productivity software.

\subsection{CAD/CAM/CAE Software}

In terms of CAD packages, for the past four years SolidWorks was used in Years 1 and 2 with Unigraphics NX3 or NX4 used in Years 3 and 4.
However, starting in September 2007, SolidWorks is being phased out in Year 1 and replaced with NX4. This is due to the fact that UOIT recently became a member of PACE - Partners for the Advancement of Collaborative Engineering Education (see http://www.pacepartners.org/). As a member of PACE, UOIT has access to a number of CAD/CAM/CAE packages including Unigraphics NX4 at little or no cost. Keeping in mind that the software costs are passed on to the students, it makes more sense to move towards using only NX4 and not both NX4 and SolidWorks.

Additional CAD/CAM/CAE packages students have access to include: Working Model 2D - a mechanism simulation package; MSC.visualNastran 4D - a motion simulation/FEA package; Adams - a motion simulation package (that will replace MSC.visualNastran 4D); NX Nastran - a FEA package, MATLAB and Simulink; Maple; and LabVIEW.

\subsection{Productivity Software}

In addition to the CAD/CAM/CAE software a number of productivity software packages are available to the students. As part of the software image all students have access to Microsoft Project for use in project planning. In addition, both Adobe Acrobat and Microsoft Office are installed. These packages, featuring presentation graphics, computerized charting, and word processing, are provided to enable students to create presentations, reports, and papers.

\subsection{Network Infrastructure}

Supporting the software on the laptops is a wireless and wired network infrastructure. The wireless infrastructure is accessible from within every campus building and many locations outside. The wired network is available in lecture halls and laboratories.

Through either the wireless or wired network, students can access course materials via WebCT Vista, UOIT's current learning management system, or library resources. The library features extensive digital resources including most of the leading technical journals, such as those from the ASME or IEEE, in online formats.

\subsection{Tablet Computers}

All engineering professors at UOIT are equipped with tablet computers whose advantages over conventional laptops have revolutionized the delivery of lectures. 
As opposed to the traditional method of writing on a chalk board and forcing students to "madly" copy everything down without listening to what is being said or the more recent approach of boring students to sleep with endless PowerPoint presentations, the tablet computer allows professors to create hybrid lectures that combine the best features of both methods. Using the tablet's pen feature, a professor can on-the-fly mark-up their lecture notes, adding comments, deriving equations, etc. However, unlike using a blackboard where the writing cannot be saved, the marked-up lecture notes using the tablet computer can be saved and then posted on WebCT Vista for students to review at their own pace. Students can now spend the lecture time focusing on what is being presented.

\section{Benefits}

The ubiquitous access to the mobile computing environment through the laptop computer adds an extra dimension to the study experience and offers numerous benefits to design engineering education.

\subsection{Access}

Although most university students have access to a computer, most students in engineering do not have access to licensed CAD/CAM/CAE packages.

Typical universities have a fixed number of desktop workstations with a fixed number of copies of licensed CAD/CAM/CAE programs. Due to budget and space limitations, it is impossible to provide enough workstations for every student enrolled in engineering. The consequence of this is that the demand for computing resources greatly exceeds the capacity of the system. Inevitably this shortage is manifested in the later part of a semester when students are trying to complete their group design projects and are forced to "battle" one another to get on to a computer. This is a huge waste of students' time which is an extremely valuable commodity in engineering programs.

In addition, students must be on campus to access this limited resource. This poses additional problems, with students spending inordinate amounts of time on campus just to try and use a computer.

The ubiquitous mobile computing environment eliminates these two major short comings. Since every student has a laptop that is equipped with all the $\mathrm{CAD} / \mathrm{CAM} / \mathrm{CAE}$ and productivity packages they need, there is never a shortage of resources. Students can then focus their energy on completing design projects and assignments.
In addition, since the software is on a laptop, students can work from virtually anywhere. Students are no longer tied to the campus, but can work from a location more suitable for their individual or group needs. It must be noted that some of the CAD/CAM/CAE software packages require access to a license server. However, as most students now have internet connections at home and free wireless access points are readily available; this is not a major drawback.

With the mobile computing environment, students have unlimited access to online course materials through WebCT Vista, textbook interactive ematerials, library reference materials that offer a combination of text, audio, and video content, the World Wide Web, e-mail, and other communication tools.

\subsection{Benefits to Design Engineering Education}

The benefits to design engineering education of the mobile computing environment are numerous.

One of the most important benefits is that the mobile computing environment facilitates group work, including work on group design projects. Students can hold virtual project meetings and have full access to all the computing tools they need. No longer are students restricted by location and limited computing resources. This is important for a university where a large number of students commute to school.

The mobile computing environment also enables design to be more readily integrated throughout all years of the curriculum. Traditionally, students would work on major group design projects in Years 3 and 4 of their programs. One reason for this is due to the limited CAD/CAM/CAE software resources most schools have. With the fully equipped laptop, there is no longer a reason to restrict major group design projects to Years 3 and 4 . In fact, they can be implemented in any year. At FEAS, there are major design courses with group design projects in every year, including Years 1 and 2 [6-8]. The pedagogical benefits of including design education as early and as often as possible throughout the curriculum have already been identified and widely recognized $[9,10]$.

The laptop program facilitates design projects in courses that traditionally did not have design projects and allows the development of novel integrated projects that span across multiple courses. 
An example at UOIT of this novel delivery is an integrated project that has been established between two courses in Year 3, namely, ENGR 3030U: Computer-Aided Design and ENGR 3270U: Kinematics and Dynamics of Machines [8]. In this integrated design project, students work on a common project between the two courses designing a mechanism to achieve some desired task. The laptop's CAD software allows the students to generate 3-D virtual prototypes and a complete set of engineering drawings for their designs, while the CAE tools allow them to perform motion analysis and FEA. The productivity software allows them to create engineering reports, maintenance manuals, and professional presentations of their designs. By bridging the project across a core design course and an analysis course, students get a better appreciation of how the design process should work.

The mobile computing environment also allows laboratories to be better utilized in fostering design engineering education. An example of this at UOIT is in the course ENGR 3390U: Mechatronics [11]. In ENGR 3390U, the laboratories have been set-up as a series of five mini-design projects, with each miniproject building upon the previous one.

For the mini-design projects, students are given the specified hardware. However, they are free to program and use the hardware in any manner they like so long as they achieve the specified task. Due to the fact that students only have access to the hardware used in the projects during their lab times, a heavy emphasis is placed on the creation of simulations of their mechatronic systems. To this end, students are required to have a functioning simulation of their system as part of their pre-lab requirements and are instructed to use the simulation of their systems to debug their designs outside of the lab time. This use of simulations in designing mechatronic systems is facilitated by the laptop learning environment.

The laptop environment also provides the opportunity to implement novel assessment techniques in design courses. For example, in ENGR 3200: Engineering Graphics and Design, ENGR 2310: Concurrent Engineering and Design, and ENGR 3030: ComputerAided Design, online testing has been implemented to supplement the traditional assessment techniques. In particular, students are tested on their ability to create design using the various CAD packages.

The final benefit of the mobile computing environment is the ability to facilitate the personal expression of students with regards to their designs.
Students have numerous opportunities for personal expression by creating web pages, posters, web casts, blogs, and videos.

\section{Challenges}

The major challenge of the mobile computing environment is the additional cost of the program that the students have to pay in order to have such a resource. Keeping the cost of the program reasonable, but still providing the best educational experience is a constant struggle. Programs such as PACE help offset some of the financial burden.

It must be noted that if students were to try to purchase the various software packages they use on their own, the total price tag would be substantially higher then the yearly fee they pay (note for 2007/08 the laptop fee is $\$ 1,532.65$ ). By also pointing out to the students the numerous pedagogical benefits of the mobile computing program, much of the perceived concerns associated with the cost of the program can be alleviated.

Another challenge is ensuring that the students effectively utilize this exceptional resource that they have at their disposal. To address this problem, a framework of digital learning modules is being developed. This is discussed in more detail in the next section.

\section{Proposed Enhancements}

Although the mobile computing environment has proven to be extremely useful to design engineering education, there are a number of enhancements the authors believe would make it an even more effective tool.

The first proposed enhancement is switching all teaching assistants (TA's) and students over to tablet computers. The benefits of using tablet computers by professors have already been shown. With tablet computers, students can create digital sketches that they can easily share with their group members and to their professors and TA's for rapid feedback, including marked up annotations done using the tablet's pen feature.

Another improvement that is already underdevelopment is a framework of explanatory selfguided step-by step learning modules that will help students to do better on their design projects [12]. These modules will be in the form of Webcasts and offline (or streaming) digital video self-learning 
instructional units with increasing levels of difficulty that will clearly demonstrate and deliver both basic as well as advanced technical hands-on information on how to prepare design engineering projects.

These modules will form the core of the curriculum and serve as exemplary, "hands-on-minds-on" model lessons that enrich the learning experience of the entire range of students. The framework of modules will be hosted on a web site at UOIT allowing students 24/7 access to them. Although certain modules are targeted for students within certain years of the program, the idea of the framework is to allow students to use it as reference source that they can access anytime during the duration of their program.

\section{Conclusions}

Over the course of the last four years a new engineering curriculum has been developed at UOIT. A key element of the curriculum is the ubiquitous mobile computing environment. The benefits of such a resource on design education are numerous. The laptop program facilitates design engineering throughout the curriculum in all years and through courses that traditionally did not have a large design component. It enables novel design education delivery such as integrated projects across multiple courses. The mobile computing environment enables students to make better use of their time and gives them unlimited access to lecture materials, library resources, and most importantly CAD/CAM/CAE and productivity software tools.

\section{Acknowledgements}

The authors are grateful for the hardware and software provided by the PACE program.

\section{References}

[1] Jacobs, H. R., 1996, "The Utilization of a Mobile Computing Environment in Undergraduate Education," in Proceedings of the $26^{\text {th }}$ Annual Conference on Frontiers in Education," November 6-9, Salt Lake City, Utah, USA, pp. 656-658.

[2] McMahon, M. and Pospisil, R., 2005, "Laptops for a Digital Lifestyle: Millennial Students and Wireless Mobile Technologies” in Balance, Fidelity, Mobility: Maintaining the Momentum? - Proceedings of the 22nd Annual Conference of the Australian Society for Computers in Learning in Tertiary Education, December 4-7, Queensland University of Technology, Brisbane, Australia, 11 pages.
[3] Smith, J. D. and Trayner, B., 2005, "Weaving Together Online and Face-To-Face Learning: A Design From A Communities Of Practice Perspective," in Proceedings of ELearn 2005, October 24-28, Vancouver, BC, Canada, 6 pages.

[4] Ellis, A., 2001, "Student-centered Collaborative learning via Face-To-Face and Asynchronous Online Communication; What is the Difference?” in Meeting at the Crossroads - Proceedings of the 18th Annual Conference of the Australian Society for Computers in Learning in Tertiary Education, December 9-12, University of Melbourne, Melbourne, Australia., pp. 169-177.

[5] Cochrane, T., 2005, "Mobilising Learning: A Primer for Utilising Wireless Palm Devices to Facilitate a Collaborative Learning Environment" in Balance, Fidelity, Mobility: Maintaining the Momentum? - Proceedings of the 22nd Annual Conference of the Australian Society for Computers in Learning in Tertiary Education, December 4-7, Queensland University of Technology, Brisbane, Australia, 7 pages.

[6] Nokleby, S. B. and Pop-Iliev, R., 2005, “A Design Challenge - Incorporating Design into The First Year Engineering Curriculum," in Proceedings of the Second CDEN International Conference on Design Education, Innovation, and Practice, July 18-20, Kananaskis, Alberta, Canada, 6 pages.

[7] Pop-Iliev, R. and Nokleby, S. B., 2005 "Concurrent Approach to Teaching Concurrent Design Engineering," in Proceedings of the Second CDEN International Conference on Design Education, Innovation, and Practice, July 18-20, Kananaskis, Alberta, Canada, 10 pages.

[8] Pop-Iliev, R. and Nokleby, S. B., 2006 "Integrated Group Design Projects: $1+1=11$," in Proceedings of the Third CDEN International Conference on Design Education, Innovation, and Practice, July 24-26, Toronto, Ontario, Canada, 6 pages.

[9] Britton, R., Charron, F., Dickinson, T., Little, P., and Stiver, W., 2004, "Design Sequence Experiences: A Panel Discussion," in Proceedings of the Inaugural CDEN Design Conference, July 29-30, Montreal, Quebec, Canada, 7 pages.

[10] Angeles, J., Britton, R., Chang, L., Charron, F., Gregson, P., Gu, P., Lawrence, P., Stiver, W., Strong, D., Stuart, P., and Thompson, B., 2004, "The Engineering Design Competency," in Proceedings of the Inaugural CDEN Design Conference, July 29-30, Montreal, Quebec, Canada, 7 pages

[11] Nokleby, S. B., 2007, “A Novel Undergraduate Mechatronics Course Featuring Hands-On Project-Based Learning," in Proceedings of the 12th World Congress on 
Mechanism and Machine Science, June 17-21, Besançon, France, 6 pages.

[12] Pop-Iliev, R. and Nokleby, S. B., 2007 "Digitally Enhancing the Project-Based Approach to Design Engineering Education," to appear in Proceedings of the International Conference on Engineering Design, ICED'07, August 28-31, Paris, France, 12 pages. 